\title{
Investigation of penetrator defect formation during high frequency induction welding in pipeline steels
}

\author{
Christos Sofras ${ }^{1,2}$, Marianthi Bouzouni ${ }^{3}$, Nikolaos Voudouris ${ }^{4}$ and Spyros Papaefthymiou ${ }^{5}$ \\ ${ }^{1}$ Laboratory for Neutron Scattering and Imaging (LNS), Paul Scherrer Institute, Villigen PSI 5232, \\ Switzerland \\ ${ }^{2}$ Ecole Polytechnique Federale de Lausanne, $\mathrm{CH}$ - 1015 Lausanne, Switzerland \\ ${ }^{3}$ ELKEME S.A., 61st km Athens-Lamia Nat. Road, 32011 Oinofyta, Viotia, Greece \\ ${ }^{4}$ CPW S.A., VI.PE Thisvis, 32010 Viotia, Greece \\ ${ }^{5}$ Laboratory of Physical Metallurgy, Division of Metallurgy and Materials, School of Mining and \\ Metallurgical Engineering, 9, Her. Polytechniou Str., Zografos, 15780 Athens, Greece
}

\begin{abstract}
The aim of this study is to investigate the formation of oxide defects known as penetrators during high frequency induction welding process of high strength low alloy pipeline steels and to correlate their formation with the steel chemical composition. Penetrators formed during the welding process can be detrimental for the impact properties of the weld seam. For this purpose, three different samples, with different chemical compositions, were intentionally produced with penetrator-type oxides and investigated. In order to characterize the oxide defect and correlate their formation with the chemical composition of the steel, optical microscopy and scanning electron microscopy paired with energy dispersive spectroscopy were employed. In addition, thermodynamic calculations were performed in order to examine whether the chemical composition of pipeline steels is prone to oxide formation. The results showed that oxides with pancake type morphology were found alongside the fusion zone of the samples. They mainly consisted of manganese and silicon. First findings on the the $\mathrm{Mn} / \mathrm{Si}$ ratio showed that the lower ratio is less susceptible to oxide formation.
\end{abstract}

\section{Introduction}

The world's ever-increasing energy demands impose new challenges in the field of oil and gas exploration, related both to the medium being transported (i.e. high $\mathrm{H}_{2} \mathrm{~S}$ content, high operating pressure) and to the environment in which the pipeline operates (i.e. low temperatures). The pipeline steels used for this application need to have excellent strength and toughness, good weldability and high corrosion resistance against $\mathrm{H}_{2} \mathrm{~S}$. [1], [2] Control of the microstructure and of the crystallographic texture is the only way to meet these requirements. Modern pipeline steel grades, utilized for this applications, are characterized by a lower carbon (C) content paired with an increased Mn content. Furthermore, microalloying elements, such as niobium $(\mathrm{Nb})$ and molybdenum $(\mathrm{Mo})$, have a significant impact through the formation of carbides, both increasing strength and aid the austenite grain refinement during thermochemical processing. In addition, typical microstructures consist of products of rapid cooling of austenite, like combinations of bainite-martensite instead of pearlite-ferrite. [1] It should be noted, that modern pipelines are also characterized by a larger wall thickness in order to operate at higher pressures. [1], [2]

High Frequency Electric Resistance Welding (HF-ERW) is a modern, widely used welding technique. Depending on the way in which the electric current is applied to the 
steel strip, it can be divided into two techniques. The first one is the High Frequency Resistance Welding, where the required current is applied by a contractor and the second one is the High Frequency Induction Welding (HFIW), where the required current is applied to the steel strip by the passage through an inductive coil. [3] The present study investigates microstructures after HFIW welding. During HFIW, the steel strip is appropriately machined in order to ensure that its edges are ideal for the welding process. Then, it passes through a series of rolls, taking the characteristic "O" shape of the pipeline. During the passage of the steel strip through the induction coil, the abutting edges are heated and they are forced together by pressure rolls. In this way, the two edges are autogenously welded together. The importance of this step of the manufacturing process is of high significance, for the quality of the manufactured pipeline. Since the whole procedure is carried out in an absence of a shielding gas atmosphere, oxides may easily form due to temperatures slightly above of the steel's melting point. During the squeezing of the edges, molten material, which as expected is characterized by a large concentration of oxides, is ejected out of the joint. In a later stage, the rejected material is mechanically removed. [2]-[4]

The formation of oxide inclusions during the HFIW is closely linked with the stage of squeezing of the abutting edges of the steel strip and they are categorized as either cold welds or penetrators. The term cold weld refers to oxide inclusions with thin film morphology that are located along the weld bond line. It is believed that cold welds usually occur when the heat input is not enough to mobilize the ejection of oxidized molten volumes out of the joint leading to insufficient melting of the steel strip. On the other hand, penetrators are oxide defects mainly consisting of iron (Fe), manganese $(\mathrm{Mn})$ and silicon (Si), with pancake type morphology, usually located along the fusion line. Penetrators usually occur when the heat input is increased and when the mill speed (the speed that the steel strip is moving) is decreased, leading many researchers to characterize them as a process induced defect. [5], [6] In an attempt to correlate the formation of penetrators with the chemical composition of the steel it is suggested that the following chemical reactions describe the formation of penetrators:

$$
\begin{aligned}
(\mathrm{FeO})+[\mathrm{Mn}] & \rightleftharpoons[\mathrm{Fe}]+(\mathrm{MnO}) \\
2(\mathrm{FeO})+[\mathrm{Si}] & \rightleftharpoons 2[\mathrm{Fe}]+\left(\mathrm{SiO}_{2}\right)
\end{aligned}
$$

, where the [ ] denotes the element's concertation in the molten iron and ( ) the slag's free oxide content. In this way, it has been observed that the $\mathrm{Mn} / \mathrm{Si}$ ratio may have a significant impact on the formation of penetrators. Oxides that lie close to the eutectic point of the diagram, should remain small during the welding process and have lower viscosity than the molten metal, making them easier to expel during the squeezing stage. For specific steel grades, it has been referenced that a $\mathrm{Mn} / \mathrm{Si}$ ratio close to eight (8) corresponds to the eutectic point of the phase diagram and leads to a small number of penetrators in the joint. [5], [7]-[10] The Mn and Si content of the steel strip, decreases at the welded joint with the heat coefficient. The heat coefficient is defined as:

$$
Q=\frac{E_{p} I_{p}}{v t}
$$

, where $E_{p}$ is the applied voltage $(\mathrm{kV}), I_{p}$ is the current $(\mathrm{A}), v$ is the welding speed $(\mathrm{m} / \mathrm{min})$ and $t$ is the wall thickness of the pipe. [4], [10] Aim of the present study is the identification and the characterization of penetrators along the bond line of HFIW pipes by means of optical and electron microscopy. Analysis of the chemical composition of the 
detected oxides and thermodynamic simulations aid the understanding of the reactions leading to the formation of penetrators. This investigation sheds light into the formation of penetrators and correlates their formation with the chemical composition of the steel.

\section{Experimental}

The weld zones of three (3) HFIW pipeline steel grades were deployed for the purpose of the present study. Specimens with penetrator-type defects were produced for the purposes of this study using selected non-optimal welding parameters. Table 1 shows the steel grade of each sample, the value of the $\mathrm{Mn} / \mathrm{Si}$ ratio of each alloy and the wall thickness. For metallographic analysis, the samples were appropriately cut, grinded and polished. Since the focus was the observation and characterization of the penetrators, etching was not performed. Initially, oxides were observed by means of optical and electron microscopy, using the "Nikon Epiphot 300" optical microscope. Detailed characterization of the detected penetrators was carried out by means of Scanning Electron Microscopy (SEM), using a "FEI XL40 SFEG" scanning electron microscope. Chemical analysis was of the oxides was done with an Energy Dispersive X Ray Spectroscopy (EDS) column attached to the scanning electron microscope. Phase diagrams of the formed oxides were produced by using the commercial software Thermo - Calc ${ }^{\circledR}[1]$.

Table 1. Grade, Mn/Si ratio \& wall thickness of the examined samples

\begin{tabular}{|c|c|c|c|}
\hline Sample ID & Steel grade & Mn/Si & $\begin{array}{c}\text { Wall thickness } \\
(\mathbf{m m})\end{array}$ \\
\hline $\mathbf{1}$ & L415ME & 7,9 & 11,10 \\
\hline $\mathbf{2}$ & L360ME & 5,24 & 11,10 \\
\hline $\mathbf{3}$ & L415ME & 5,52 & 14,30 \\
\hline
\end{tabular}

\section{Results and Discussion}

Fig. 1 shows optical micrographs of the weld zone of sample 1. As it is evident, numerous oxides with elongated morphology were detected along the fusion line. EDS analysis (Fig. 2) revealed that the oxides mainly consisted of $\mathrm{Mn}$ and $\mathrm{Si}$, making certain their classification as penetrators.
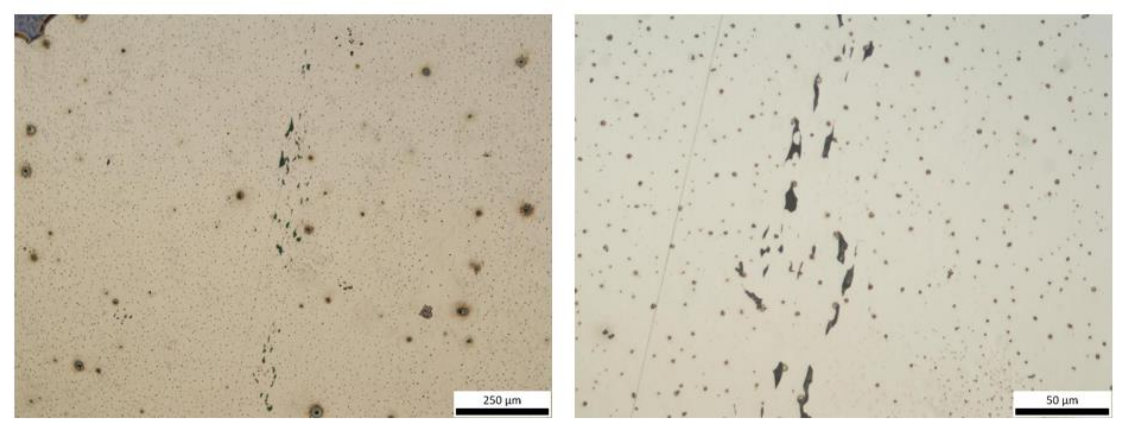

Fig. 1. Optical micrographs of sample 1 


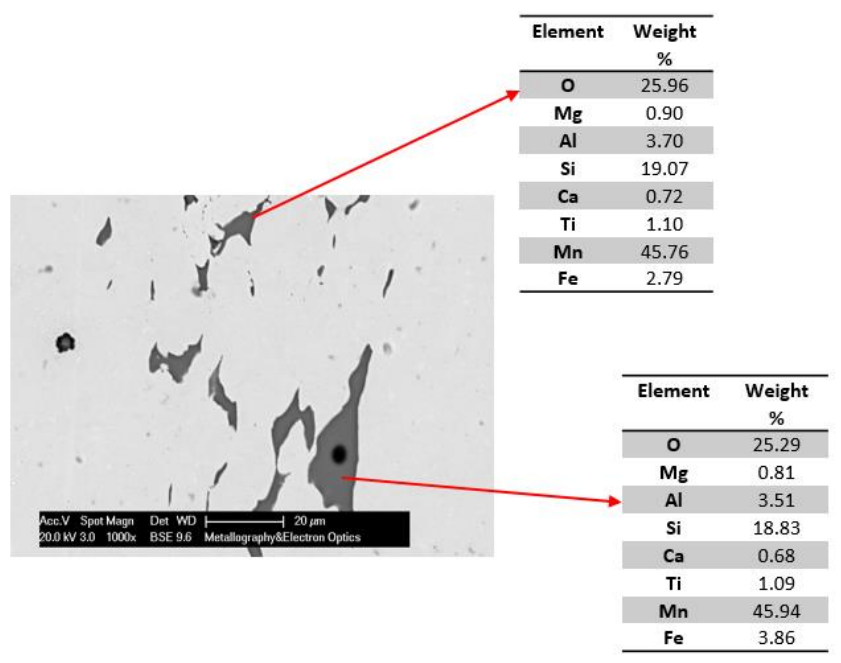

Fig. 2. SEM micrograph and EDS analysis of sample 1

Sample 2 displayed a large amount of oxides along the fusion line (Fig 3.). Yet again, they mainly consisted of $\mathrm{Mn}$ and $\mathrm{Si}$ and they were categorized as penetrators. Particular interest showed an elongated crack-like morphology, which was detected in between the various oxides. It should be noted that the edge one of this morphology reached the outer surface of the sample. Fig. 4 shows the results of EDS elemental mapping for the distribution of $\mathrm{Mn}, \mathrm{Si}$ and $\mathrm{O}$ in this particular area of interest. It can be observed that the area along this elongated morphology is crowded with oxide inclusions, rich in $\mathrm{Mn}$ and $\mathrm{Si}$. In addition, it is safe to say that segregation of Mn along this region can also be observed. Existing literature [11] suggests that the main causes for the formation of cracks in this type of welds is inhomogeneity in the microstructure between the different welding zones, segregation of elements such as $\mathrm{Mn}$ and oxide clusters. It is suggested [11] that oxide inclusions serve as stress concertation spots and lead to the nucleation of voids. Due to the high deformation stresses, in which the steel strip is subjected to during the forming process, cracks can form at the penetrators and propagate in the neighborhood of the oxide clusters. This phenomenon is amplified in the weld region, where the mechanical stresses are also accompanied by the thermal stresses imposed by welding. Since the stresses are greater in the outer surface of the pipeline, the cracks tend to propagate from the center to the outer surface of the pipeline [11]. The case of the elongated morphology that was detected in sample 2 fits well the above analysis. The numerous oxides that were found in its vicinity and the small segregation of Mn that was detected by the EDS elemental mapping, can serve as nucleation sites for voids. Also, it was detected along the weld line and its one side reached the sample edge, hinting that its propagation was the effect of the combination of mechanical and thermal stresses and it followed the stress maxima along the sample. On the other hand, one other possible explanation for the existence of this morphology could be the detachment of a large number of oxides during the metallographic preparation, leading to the formation of this elongated void. 

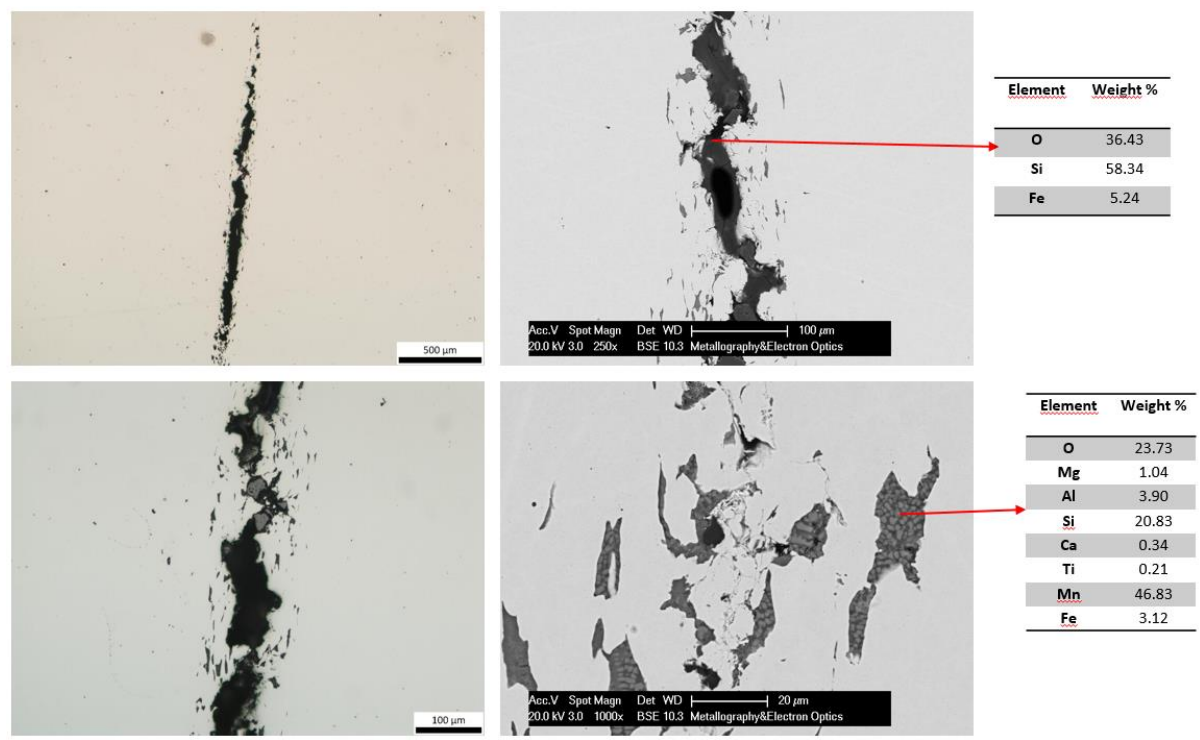

Fig. 3. Optical micrographs of sample 2 (left), SEM micrographs and EDS analysis of sample 2 (right)

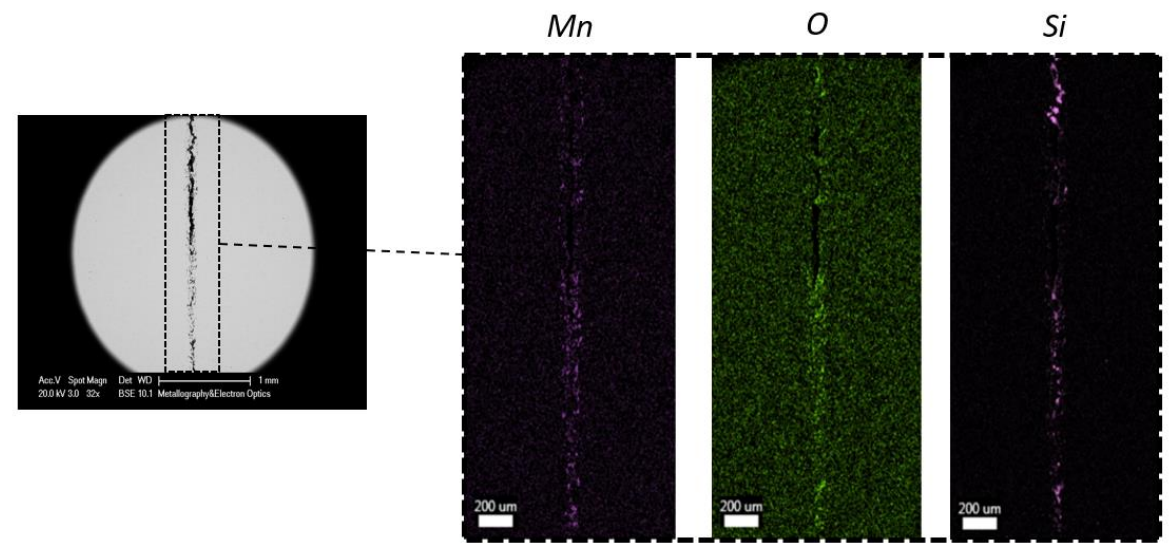

Fig. 4. EDS elemental mapping results for sample 2

Fig. 5 shows micrographs captured with the scanning electron microscope and the results of the EDS analysis for sample 3. Interestingly enough, this sample displayed the least amount of penetrators among the examined samples. This is contradictory to the findings and suggestions of earlier studies, since the $\mathrm{Mn} / \mathrm{Si}$ ratio of the sample is 5.52. A possible explanation to this observation is that oxides formed during welding are in liquid phase with lower viscosity compared to the liquid metal which facilitates their removal during squeezing. However this assumption should be further investigated in multiple sections in similar sample in order to reach safe conclusions. 

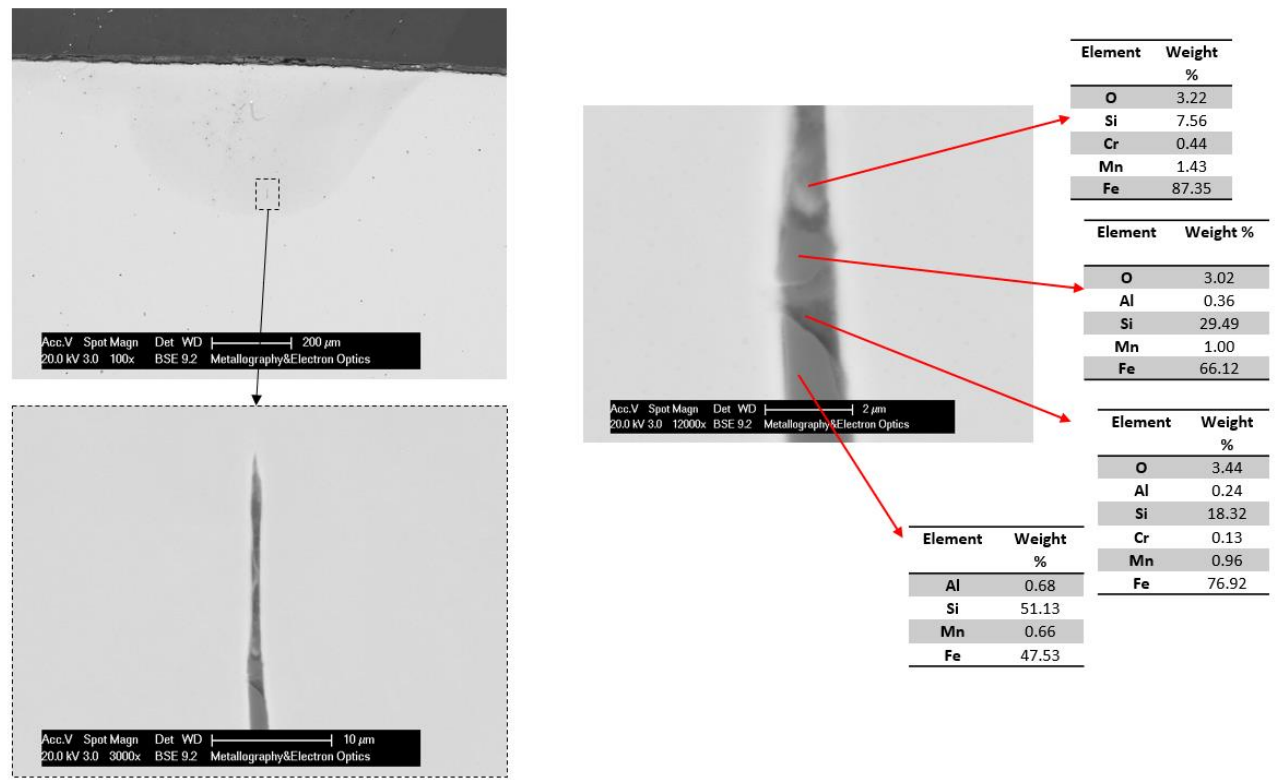

Fig. 5. SEM micrographs and EDS analysis of sample 3

Fig. 6 shows the thermodynamically calculated $\mathrm{MnO}-\mathrm{SiO}_{2}$ phase diagrams. The correlation of the $\mathrm{Mn} / \mathrm{Si}$ ratio with the wt $\%$ of $\mathrm{SiO}_{2}$ was done by calculating the chemical composition of the oxides detected in each studied sample. For the samples that were used for the purposes of the present study it is observed that as the composition of the formed oxides approaches the eutectic point of the diagram, as the $\mathrm{Mn} / \mathrm{Si}$ ratio is strictly decreasing. It is important to maintain oxides in liquid form since their removal will be facilitated. Samples witha $\mathrm{Mn} / \mathrm{Si}$ ratio equal to 8 for the certain chemical composition may lead to formation of penetrators at welding. 


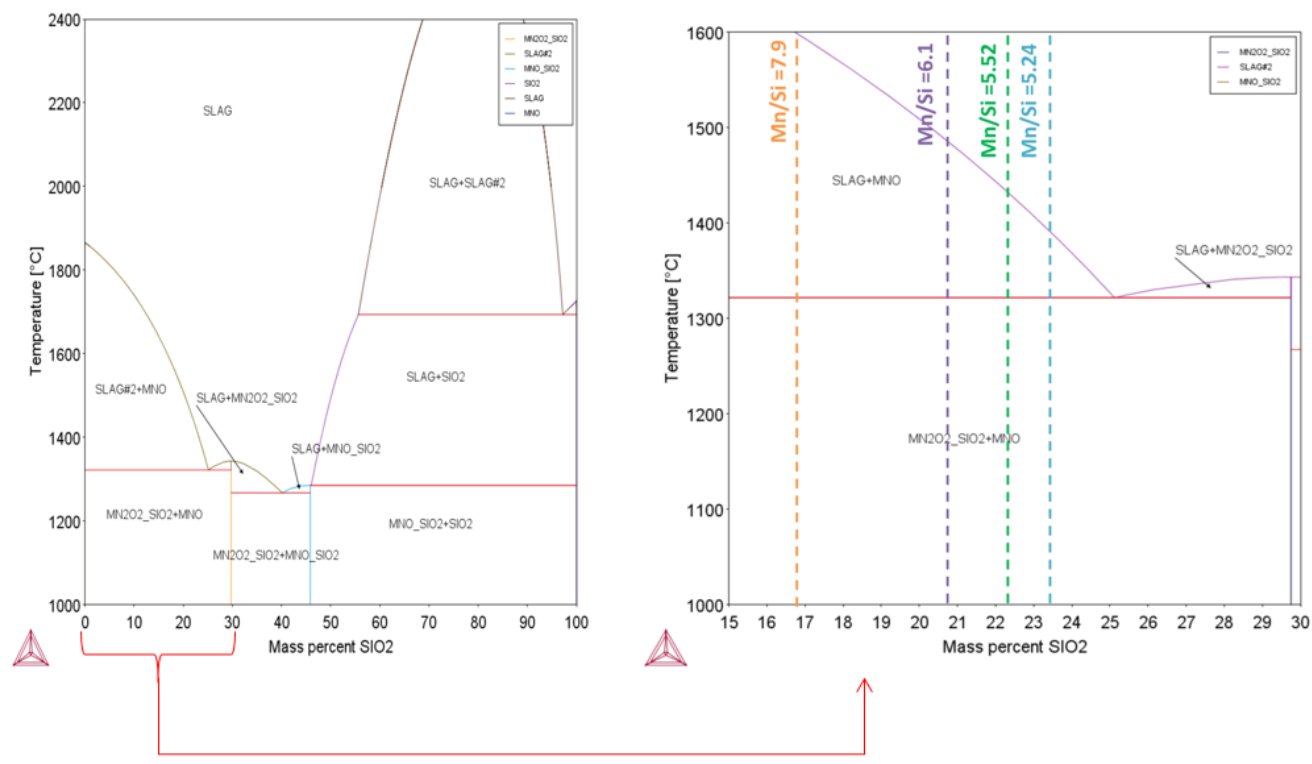

Fig. 6. Calculated binary phase diagram of $\mathrm{MnO}-\mathrm{SiO}_{2}$ system.

\section{Conclusions}

The analysis of formed oxide inclusions of HFIW welds with different compositions and thicknesses revealed that oxides in fusion zone were mainly comprised from $\mathrm{Mn}, \mathrm{Si}$ and secondly from aluminium (Al). Furthermore, it was observed that the presence of oxides in the fusion line of the weld could act as stress raiser (concentration points at oxide clusters) and might with certainty lead to cracking when external or thermal stresses will be applied. Additionally, the reduction of $\mathrm{Mn} / \mathrm{Si}$ ratio for the provided steel grades should, at least theoretically, leads to decrease in $\mathrm{T}_{\text {liq }}$ (eutectic point of oxides phase diagram $\mathrm{Mn}-\mathrm{Si}$ ) favoring the formation of oxides with eutectic composition in the fusion zone during welding. The formation of oxides with eutectic composition leads to improved weldability since the low viscosity of oxides facilitates their removal from the melt during squeeze out. However, further work is necessary in order to achieve firm correlations between the thermodynamic predictions and the actual chemical compositions of penetrator-type oxides. 


\section{References}

[1] R. H. Petrov, J. J. Jonas, L. A. I. Kestens, and J. M. Gray, "Microstructure and Texture Development in Pipeline Steels," Oil Gas Pipelines Integr. Saf. Handb., pp. 157-186, Apr. 2015, doi: 10.1002/9781119019213.CH10.

[2] S. Papaefthymiou, "Industrial Pipeline Welding," 2021, doi: 10.1007/978-3-03063986-0_12.

[3] H. Brauer and H. Löbbe, "Pipe Manufacture-ERW Pipe," Oil Gas Pipelines Integr. Saf. Handb., pp. 203-210, Apr. 2015, doi: 10.1002/9781119019213.CH14.

[4] Y. Pei, "High Frequency Induction Welding \& Post-Welding Heat Treatment of Steel Pipes," 2011.

[5] J. Choi, Y. S. Chang, C. Kim, J.-S. Oh, and Y.-S. Kim, "Penetrator formation mechanisms during high-frequency electric resistance welding," undefined, 2004.

[6] C. M. Kim and J. K. Kim, "The effect of electromagnetic forces on the penetrator formation during high-frequency electric resistance welding," J. Mater. Process. Technol., vol. 209, no. 2, pp. 838-846, Jan. 2009, doi:

10.1016/J.JMATPROTEC.2008.02.079.

[7] H. Haga, K. Aoki, and T. Sato, "Welding Phenomena and Welding Mechanisms in High Frequency Electric Resistance Welding-1st Report High speed camera studies show the existence of three types of welding phenomena, and properly chosen parameters determine which type of phenomenon appears," Weld. J. (Miami, Fla), pp. 208-212, 1980.

[8] H. Haga, K. Aoki, and T. Sato, "MECHANISMS OF FORMATION OF WELD DEFECTS IN HIGH-FREQUENCY ELECTRIC RESISTANCE WELDING.," Weld. J. (Miami, Fla), vol. 60, no. 6, pp. 104-109, 1981.

[9] M. H. Shin, J. M. Han, Y. S. Lee, and H. W. Kang, "Study on Defect Formation Mechanisms in ERW for API Steel," Proc. Bienn. Int. Pipeline Conf. IPC, vol. 3, Dec. 2014, doi: 10.1115/IPC2014-33082.

[10] E. Yokoyama, M. Yamagata, N. Kano, and S. Watanabe, "Effects on Penetrator Defect Occurrence of Welding Conditions and Mn/Si Ratio of ERW High Manganese Line Pipe," 1978.

[11] M. S. Joo, K.-M. Noh, W.-K. Kim, J.-H. Bae, and C.-S. Lee, “A Study of Metallurgical Factors for Defect Formation in Electric Resistance Welded API Steel Pipes," doi: 10.1007/s40553-015-0049-6. 